
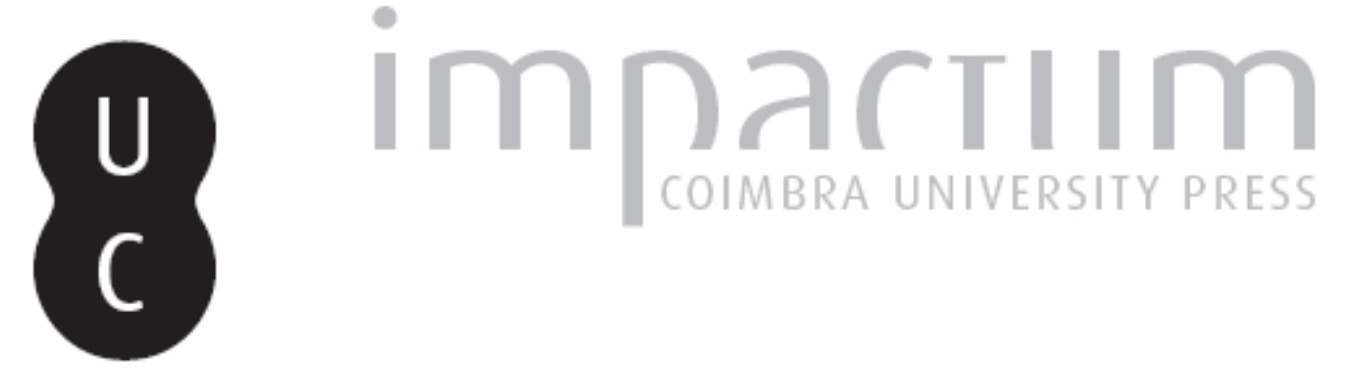

\title{
[Recensão a] Science for disaster risk management 2017. Knowing better and losing less
}
Autor(es):
Almeida, A. Betâmio
Publicado por: Imprensa da Universidade de Coimbra
URL
persistente:
URI:http://hdl.handle.net/10316.2/43281
DOI:
DOI:https://doi.org/10.14195/1647-7723_25-1_14
Accessed : $\quad$ 26-Apr-2023 11:48:28

A navegação consulta e descarregamento dos títulos inseridos nas Bibliotecas Digitais UC Digitalis, UC Pombalina e UC Impactum, pressupõem a aceitação plena e sem reservas dos Termos e Condições de Uso destas Bibliotecas Digitais, disponíveis em https://digitalis.uc.pt/pt-pt/termos.

Conforme exposto nos referidos Termos e Condições de Uso, o descarregamento de títulos de acesso restrito requer uma licença válida de autorização devendo o utilizador aceder ao(s) documento(s) a partir de um endereço de IP da instituição detentora da supramencionada licença.

Ao utilizador é apenas permitido o descarregamento para uso pessoal, pelo que o emprego do(s) título(s) descarregado(s) para outro fim, designadamente comercial, carece de autorização do respetivo autor ou editor da obra.

Na medida em que todas as obras da UC Digitalis se encontram protegidas pelo Código do Direito de Autor e Direitos Conexos e demais legislação aplicável, toda a cópia, parcial ou total, deste documento, nos casos em que é legalmente admitida, deverá conter ou fazer-se acompanhar por este aviso.

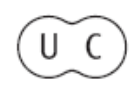


territorium/25w|.

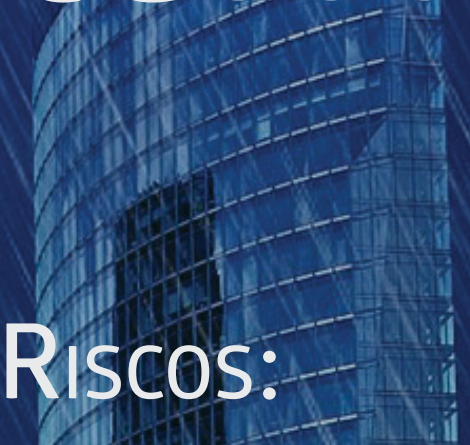

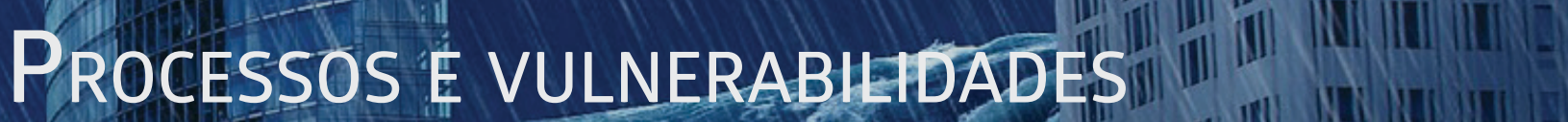

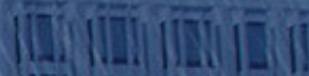
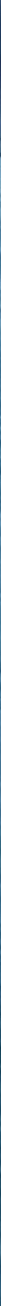

Imprensa da Universidade de Coimbra

Associação Portuguesa de Riscos, Prevenção e Segurança

2018 


\title{
SCIENCE FOR DISASTER RISK MANAGEMENT 2017 KNOWING BETTER AND LOSING LESS
}

\author{
A. Betâmio de Almeida \\ Universidade de Lisboa (Portugal) \\ betamio.almeida@tecnico.ulisboa.pt
}

\section{Introdução}

Sob a égide da UE (Directorate-General for Joint Research Centre, JRC), o recém criado Disaster Risk Management Knowledge Center (DRMKC) elaborou (em 2017) um documento com o título Science for Disaster Risk Management (escrito em inglês), designado no presente texto por SDRM, com o objetivo de proporcionar uma revisão do estado dos conhecimentos dando particular ênfase à contribuição da ciência. O SDRM pretende apresentar, de um modo sintético, as evidências científicas dos processos associados a diferentes riscos com base em conhecimentos ou evidências atualizadas. Estes conhecimentos resultam de projetos de investigação da UE e de outras atividades relevantes a nível nacional e internacional.

O SDRM pode ser considerado como um misto de síntese do "estado da arte" e de guia orientador para desenvolvimentos futuros nos domínios em causa. Salientase o facto de o tema ser a gestão do risco de "disasters". Não obstante o SDRM não definir com rigor o âmbito temático e as definições dos termos utilizados, entende-se que o mesmo pretende focar a atenção nos eventos que incindem em áreas territoriais significativas e que podem ter consequências relevantes. Não estão incluídos os eventos resultantes de atos de sabotagem ou de terrorismo.

Para a Cruz Vermelha Internacional, " $a$ disaster is a calamitous event resulting in loss of life, great human suffering and distress, and large-scale material damage". Em Portugal, a Lei de Bases da Proteção Civil (Lein ${ }^{\circ} 27 / 2006$, de 3 de Julho) adopta a designação de catástrofe para um acidente grave com estas características. Nesta conformidade, considera-se mais adequada, no contexto nacional, a designação de catástrofe como tradução do termo "disaster" utilizado no SDRM.

O âmbito do documento é, assim, muito amplo mas não tem a pretensão de ser exaustivo. Na verdade, são descritos 17 tipos de riscos considerados relevantes mas não será difícil encontrar outros riscos que poderiam ter sido considerados.

O SDRM tem 554 páginas e o texto está estruturado em seis capítulos em que são abordados 14 tipos de riscos de catástrofes. Quatro editores coordenaram a obra que teve a colaboração de 273 especialistas de 26 países (a maioria da UE, incluindo Portugal) e de 172 organizações. Cada capítulo é da responsabilidade de um conjunto de autores. Existe um resumo (Sumário Executivo) com 59 páginas. É uma obra de grande fôlego e que pretende ser uma contribuição de relevo da UE no designado "Science and Technology Roadmap" do "Sendai Framework for Disaster Risk Reduction".

A presente recensão compreende uma apreciação geral em que se destacam as principais caraterísticas do documento, uma apreciação pormenorizada na qual se apresenta de forma resumida o conteúdo de cada capítulo e, para terminar, apresentam-se as considerações do autor da recensão.

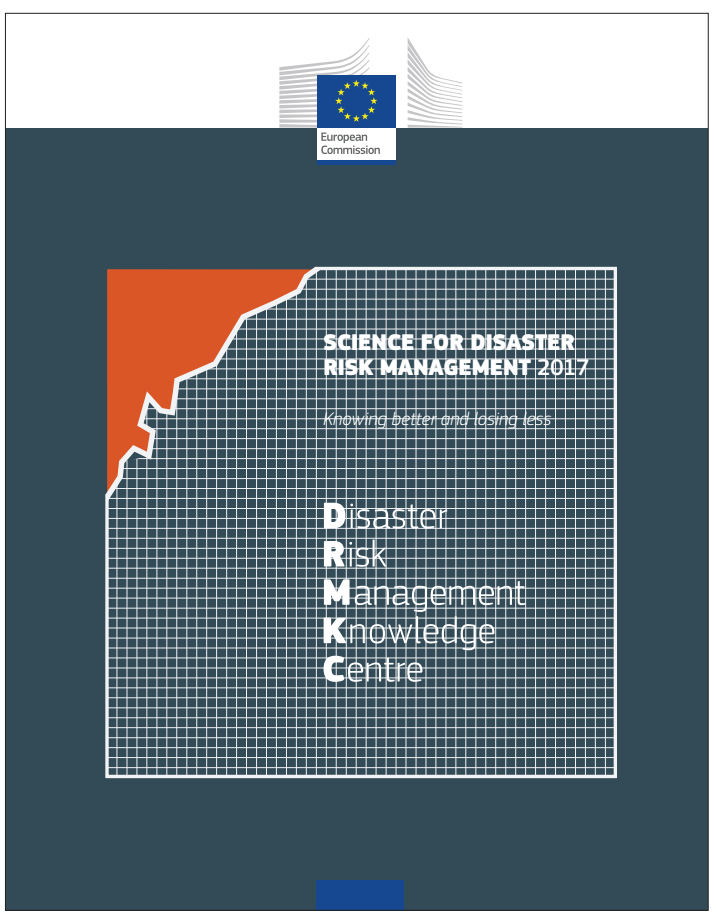

Fig. 1 - Frontispício do relatório: Science for Disaster Risk Management (Fonte: http://drmkc.jrc.ec.europa.eu/ knowledge/Challenges-Sharing).

Fig. 1 - Frontispiece of the report: Science for Disaster Risk Management (Source: http://drmkc.jrc.ec.europa.eu/ knowledge/Challenges-Sharing). 


\section{Apreciação na generalidade}

O SDRM destina-se a profissionais, políticos e especialistas em proteção civil e políticas de redução do risco de catástrofes. Em conformidade com a filosofia adotada no novo centro da UE (DRMKC), o SDRM pretende apresentar ou propor uma "ponte" entre a "Situação Atual" e os "Desafios Futuros". Essa ponte abrange os seguintes elementos estruturais: compreensão dos riscos de catástrofes, comunicação do risco de desastre e gestão do risco de catástrofes. 0 cimento dessa ponte é a ciência (multidisciplinar) sendo realçados três instrumentos metodológicos: Parcerias, Conhecimento e Inovação.

É de referir que o SDRM, apesar de incidir com especial ênfase na Europa, não fica confinado a este continente. Com efeito, o SDRM pode ser considerado um documento internacional e global.

Da leitura do SDRM salientam-se os seguintes aspetos relevantes:

- Contém informação atualizada sobre a caraterização dos diferentes tipos de risco de catástrofes considerados e as metodologias recentes aplicáveis na análise e gestão desses riscos. A tentativa de harmonização metodológica é muito positiva;

- As referências bibliográficas, por capítulo, são muito numerosas e atuais possibilitando uma pesquisa mais aprofundada ao leitor interessado. Constitui, assim, um bom suporte de trabalho;

- $\quad 0$ texto é de leitura muito fácil e agradável, exceto em algumas partes (poucas) em que é mais denso e um pouco confuso. Não tem expressões matemáticas mas contém um conjunto de figuras que exemplificam a aplicação de metodologias referidas no texto ou apresentam diagramas que explicam conceitos ou a estruturação de sistemas de análise;

- Os autores tentaram, dentro do possível, aplicar aos diferentes riscos uma estrutura metodológica sustentada cientificamente e consistente com o definido no primeiro Capítulo (estruturação metodológica). Neste aspeto, é de louvar o esforço de coordenação metodológica multidisciplinar apesar de não ter sido possível homogeneizar ou uniformizar a caraterização dos diferentes tipos de riscos;

- Os potenciais efeitos da mudança climática são considerados de um modo sistemático nas análises dos riscos sempre que tal se justifica;

- Destaca-se no SDRM uma referência alargada e sistematizada aos acontecimentos "multirriscos", um aspeto envolvendo a interação de diferentes causas e efeitos. Um tema que pode ser considerado inovador;

- O SDRM tem um aspeto dinâmico na medida em que convoca o leitor para desenvolvimentos futuros e propõe caminhos inovadores e prioritários a percorrer.
O texto oferece ao leitor uma visão muito ampla e integrada dos processos físicos associados aos diferentes tipos de catástrofes e pode ser uma excelente ajuda ao especialista académico ou ao profissional no domínio da gestão do risco.

Não obstante os Capítulos terem diferentes e múltiplos autores, o estilo mantém-se suficientemente uniforme.

\section{Apreciação pormenorizada}

Para além de alguma divulgação institucional, o SDRM tem seis capítulos que constituem o cerne do documento, a saber:

- Capítulo 1 - Current status of disaster risk management and policy frameworks;

- Capítulo 2 - Understanding disaster risk: risk assessment methodologies and examples:

- Capítulo 3 - Understanding disaster risk: hazard related risk issues.

- Capítulo 4 - Communicating disaster risk;

- Capítulo 5 - Managing disaster risk;

- Capítulo 6 - Future challenges of disaster risk management.

\section{Estado Atual da Gestão do Risco de Catástrofes}

O Capítulo 1 tem por objetivo a apresentação do estado atual da gestão do risco de catástrofes a nível mundial. Os impactos económicos e sociais das catástrofes são evidenciados e faz-se referência à incapacidade atual de cada país poder enfrentar todos os tipos de risco. São referidas quatro razões para os impactos das catástrofes aumentarem de importância:

- Mudança climática;

- Urbanização crescente e rápida;

- $\quad$ Aumento da população;

- Degradação ambiental.

A necessidade da cooperação internacional é, assim, considerada essencial. As atividades e ações mais recentes da ONU e da UE neste campo são evidenciadas.

Segundo o SDRM, as estratégias para redução do risco de catástrofes estão muito ligadas às estratégias de adaptação à mudança climática. Estas estratégias estão associadas ao conhecimento científico e este depende de dados fiáveis sobre o ambiente. Melhorar os dados relativos a perdas (económicas) e danos (em infraestruturas) é também fundamental para permitir a aplicação de metodologias e modelos robustos para simulação de cenários e avaliação de riscos. Com o conhecimento científico e os dados é possível selecionar cenários de potenciais catástrofes que possibilitem a escolha de medidas de adaptação convenientes. A interface ciência-políticas públicas é, assim, realçada. 
A investigação e o conhecimento são o suporte das medidas de gestão de crises, incluindo as fases de preparação e de resposta a crises. A aplicação dessas medidas tem contribuído para que as perdas de vidas humanas e de valores económicos sejam menores. Considera-se, no entanto, que a prevenção deve ser o primeiro patamar de ação.

É preconizado o reforço dos sistemas públicos de saúde para atuarem em situações de emergência, em particular na resposta a emergências provocadas por agentes ambientais, químicos, biológicos e de origem desconhecida. Referência especial às instalações nucleares (na UE) tendo em conta o que se passou na central de Fukushima, no Japão, em 2011. Uma referência especial é também feita ao sector da água (eventos hidrometeorológicos extremos, cheias, secas e proteção de zonas marítimas) e à Diretiva da UE relativa a inundações.

A previsão e alerta precoces são consideradas essenciais para a diminuição dos riscos de catástrofes (mitigação dos efeitos ou consequências). O SDRM cita os exemplos de sistemas transnacionais de alerta para fogos florestais e cheias, saúde pública e informação médica, avaliação de tsunamis e secas.

O apoio humanitário é fundamental no pós-catástrofe, em particular o apoio a países menos desenvolvidos ou economicamente fracos.

É referido que o Quadro de Sendai das Nações Unidas para a gestão do risco de catástrofes modifica a ênfase da gestão do risco orientada para a resposta aos eventos para uma gestão orientada para a mitigação do risco de catástrofes, com uma interface mais sistemática e reforçada de ciência-política.

$\mathrm{Na}$ perspetiva da ocorrência de catástrofes mais frequentes e severas torna-se evidente e indispensável na gestão dos riscos uma crescente dependência relativamente aos conhecimentos e ao acesso a dados existentes a diferentes níveis. Impõe-se saber transpor a complexidade do discurso científico em resultados úteis e inovadores na gestão dos riscos.

Após este Capítulo 1, introdutório e com um cariz bastante institucional nomeadamente no que respeita a UE, seguese um capítulo muito importante e interessante.

\section{Avaliação e Análise do Risco}

O Capítulo 2 pretende contribuir para uma estruturação teórica da avaliação e análise do risco. Para além de uma síntese do "estado da arte" no que respeita às metodologias mais relevantes que são aplicadas, o SDRM apresenta a estruturação considerada mais adequada e que é adotada nos Capítulos seguintes.

Como seria de esperar, o Capítulo 2 começa com a definição de Risco e considera o Risco, de acordo com a definição adotada em Sendai e a definição da UNISDR (2017), como sendo a resultante de três componentes fundamentais (p.40):

- $\quad$ "Hazard"1 (ou PIPP), que traduz a probabilidade de ocorrência de um processo potencialmente danoso com uma determinada intensidade ou magnitude;

- Exposição, que corresponde ao conjunto de valores (pessoas, bens económicos ou patrimoniais, natureza, entre outros) sujeitos ou expostos ao impacto do PIPP;

- Vulnerabilidade, que traduz o grau de dano (físico, tangivel ou intangível) ou de perdas económicas, diretas ou indiretas.

De acordo com o SDRM, a componente Capacidade ${ }^{2}$ (como sendo a caraterística associada à capacidade de recuperação pós- catástrofe) considerada em Sendai pode ser incorporada na Vulnerabilidade.

É conhecido que o conceito Vulnerabilidade e a respectiva relação com a Exposição ainda não têm uma definição consensual entre os especialistas. Este aspecto evidencia-se também no SDRM. Enquanto na p. 40 e em diversas partes do texto se entende que Hazard, Exposição e Vulnerabilidade são componentes distintas e autónomas do risco (ver Figuras nas p. 76 e 77), com direito a subcapítulos distintos (2.2 e 2.3), em outras partes do SDRM tal não acontece (exemplo da Figura 2.10 na p. 72). Uma das diferenças conceptuais está na definição da Vulnerabilidade como grau de perdas ou danos (adimensional) como se exemplifica na Figura 2.13 (p. 79) ou como envolvente de um conjunto de conceitos operacionais (exposição, susceptibilidade ou fragilidade e resiliência) como na Figura $2.10^{3}$. Mesmo considerando que é uma mera questão de terminologia, conclui-se, tal

10 termo Hazard é difícil de ser traduzido para português. Sabemos que em termos operacionais corresponde a um acontecimento com uma determinada intensidade ou magnitude danosa ao qual é atribuída uma probabilidade (composta) de ocorrência. É essa probabilidade que permite o cálculo do valor expectável das consequências. Para evitar a escrita do termo "hazard" adopta-se no presente texto o termo Processo incerto Potencialmente Perigoso ou PIPP.

20 termo Capacidade pode considerar-se, neste contexto, como equivalente ao termo designado por resiliência. Pode incluir as medidas de prevenção e de minimização das consequências.

3 A ciência do risco e a análise do risco desenvolveram-se a partir de diferentes disciplinas e escolas científicas o que explica as diferentes opções conceptuais. 0 autor da recensão apoia a conceptualização do SDRM apresentada na p. 40 e a definição de Vulnerabilidade como grau de perdas ou danos adimensional. Esta definição está contemplada no "Guia Metodológico para a Produção de Cartografia Municipal de Risco...” (ANPC e Direcção-Geral do Ordenamento do Território e Desenvolvimento Urbano e Instituto Geográfico Português, 2009) no Quadro 1 (p. 21) e Figura 2 (p.22). Nesta conformidade, a análise quantitativa do risco, envolvendo probabilidades e vulnerabilidades adimensionais, conduz a que, por razões de coerência dimensional, a exposição deva ficar destacada para permitir que o risco resultante da formulação adoptada tenha as dimensões ou as unidades das grandezas que caracterizam as perdas ou danos associados aos PIPP. 
como em outros aspectos, que a coordenação científica do SDRM não conseguiu um resultado totalmente consistente ou coerente.

Assinala-se a preocupação do SDRM em chamar a atenção para as incertezas e o caráter dinâmico das componentes do Risco, nomeadamente as alterações da Exposição e da Vulnerabilidade com o tempo ${ }^{4}$. A pressão da percepção pública relativa aos riscos pode influenciar a seleção de medidas prioritárias em detrimento de metodologias baseadas na avaliação de custos-benefícios tendo em conta a relativa limitação de recursos disponíveis. 0 SDRM realça a importância da aplicação de metodologias científicas na avaliação dos riscos mas avisa: as decisões de uma gestão do risco são, no final, políticas e que é impossível eliminar completamente um risco ${ }^{5}$.

A avaliação do risco deve ser um processo estruturado e suficientemente abrangente e transparente. O SDRM apoia-se na experiência da indústria seguradora: até 1980 a avaliação do risco era baseada na experiência histórica e em regras empíricas. Contudo, a necessidade de considerar eventos extremos ou raros, nomeadamente em resultado da mudança climática e as mudanças rápidas da sociedade tornam o conhecimento histórico e empírico insuficiente, De acordo com o SDRM, o artigo de Don Friedman, em 1984, marcou uma viragem (na indústria dos seguros) na metodologia a seguir na avaliação do risco de catástrofes. Esta metodologia adota composição do risco em PIPP, Exposição e Vulnerabilidade e a consideração probabilística dos acontecimentos e dos processos envolvidos 6 .

Nesta parte do texto nota-se, assim, a influência ou a visão metodológica da indústria seguradora.

Para aplicar as metodologias mais adequadas utilizam-se modelos computacionais complexos havendo a tendência para aceitar os resultados sem ter em conta essa complexidade e as incertezas inerentes. A exigência de dados com qualidade torna-se indispensável. No entanto, o próprio processo de modelação e avaliação do risco já é muito positivo pois potencia um conhecimento mais pormenorizado das situações e permite a identificação de problemas que poderiam estar ocultos. $\mathrm{Na}$ indústria dos seguros, a alteração das metodologias de avaliação do risco teve como consequência o aumento significativo dos recursos humanos dedicados à análise dos riscos ${ }^{7}$. Na sequência destas avaliações e análises mais complexas e completas, passou a ser necessário definir critérios de aceitabilidade e tolerância de riscos (equilibrando, em alguns domínios, o designado apetite de risco). No caso dos acontecimentos desencadeados por fenómenos naturais que não possam ser controlados na origem, o cumprimento desses critérios pode implicar a redução da Exposição e da Vulnerabilidade.

A identificação ou seleção de potenciais situações que possam realizar um risco é particularmente relevante. $\mathrm{Na}$ verdade, há que considerar o maior número possível de cenários conducentes a catástrofes, os que já aconteceram e os que poderão acontecer no futuro. Há aqui um fator subjetivo ou de experiência pessoal que é importante.

Não há um método de avaliação ou de análise do risco universal. O SDRM refere um conjunto de métodos conhecidos qualitativos ou empíricos, semi-quantitativos e quantitativos ou probabilísticos (nomeadamente com aplicação do método de Monte Carlo). São referidos os métodos aproximados baseados em indicadores e matrizes de risco e os métodos conducentes a curvas probabilísticas do risco que relacionam consequências com probabilidades de ocorrência anuais (Figuras 2.23 e 2.24). Estas curvas podem ser consideradas o tipo de representação mais completo, exigente e consistente com a definição e análise quantitativa dos riscos.

Uma avaliação rigorosa de riscos exige uma modelação científica dos PIPP e um entendimento correto do conceito risco e de probabilidades. A modelação pode

aconselhar a decisão política mas os decisores devem interpretar e conhecer as limitações dos modelos sem juízos de ordem moral.

O Capítulo 2 inclui as definições e a apresentação das metodologias de avaliação das componentes fundamentais do risco, Exposição e Vulnerabilidade, nomeadamente avaliação de perdas e danos. O SDRM faz referência a inovações e a exemplos concretos. Atendendo à dificuldade ou impossibilidade de controlar alguns processos naturais que estão na origem de catástrofes, há que preparar as comunidades para um melhor controlo da Exposição e das Vulnerabilidades. Este Capítulo termina com uma descrição sistematizada da avaliação de "multihazards" e "multirisks", ou seja a avaliação de combinações

4 A consideração das probabilidades e períodos de retorno já acontecia em alguns domínios nomeadamente, por exemplo, no controlo de cheias. No entanto, na Engenharia, procurava-se mais a avaliação da Segurança. O conceito de risco não foi muito aplicado até finais do séc. XX.

5 Esta afirmação pode ser considerada verdadeira no quadro dos acontecimentos possíveis de ocorrer. O risco pode ser nulo no caso de se conseguir demonstrar a impossibilidade de ocorrência ou a impossibilidade de exposição a um PIPP ou quando a vulnerabilidade, como grau de perdas ou danos no exposto, pode ser considerada nula face à intensidade dos impactos decorrentes do processo.

6 A consideração das probabilidades e períodos de retorno já acontecia em alguns domínios nomeadamente, por exemplo, no controlo de cheias. No entanto, na Engenharia, procurava-se mais a avaliação da Segurança. O conceito de risco não foi muito aplicado até finais do séc. XX.

7 Esta afirmação pode também ser aplicada ao sistema financeiro, aos bancos, e a outras instituições financeiras. Também em muitos outros sectores a análise e a gestão do risco conheceram, no final do séc. XX, um grande desenvolvimento e aceitação por parte de decisores políticos. 
interligadas de processos e de riscos. Trata-se de apresentar conceitos inovadores relacionados com a interação de diferentes processos e com a variabilidade (no tempo) das condições de análise. A relativa complexidade do tema não é fácil de transmitir sem a utilização de uma linguagem matemática adequada. No nosso entender, o texto do SDRM não propicia a compreensão fácil dos conceitos associados nem do modo de aplicação dos mesmos.

Um documento que tem como um dos objetivos a aplicação da ciência à gestão dos riscos tem a obrigação de apresentar os conceitos de forma consistente e o mais rigorosa possível. Contudo, é compreensível que o elevado número de autores torne difícil o controlo da consistência das sucessivas formas de apresentar ou definir os conceitos. Para exemplificar este aspeto, registamos o modo inconsistente como é referido o conceito período de retorno ao longo do documento.

\section{Referências ao Período de Retorno}

Conforme foi referido, o texto do SDRM apresenta uma coerência de estilo e um esforço para garantir o rigor científico. No entanto, podem ser detetadas algumas falhas nomeadamente nas referências ao período de retorno. 0 conceito de período de retorno é usualmente vítima de mal entendidos pelo que se torna importante que esse conceito seja bem definido e interpretado ao longo de um documento. No entanto, em partes diferentes do texto do SDRM encontramos frases relacionadas com o período de retorno que potenciam o leitor menos avisado a uma interpretação menos correta:

- "A 1 in 100 event" could happen tomorrow" (p.12). Presume-se que os autores referem um acontecimento com o período de retorno de 100 anos mas não assinalam o período de tempo correspondente à probabilidade de 0,01. Admitese que seria a probabilidade de excedência anual. No entanto, é aceitável afirmar que esse acontecimento pode ocorrer em "qualquer momento”, não existindo uma restrição rígida à respetiva ocorrência;

- "A 1-in-200 year loss is the worst loss that can be expected every 200 years, i.e. a loss with a return period of 200 years" (p.55). Esta afirmação pode induzir uma ideia errada: o evento com o período de retorno de 200 anos seria o pior que pode ocorrer em cada 200 anos o qual ocorreria uma vez em cada 200 anos. Na verdade, esse acontecimento tem a particularidade de ocorrer, em média, cada 200 anos de acordo com o padrão estacionário de ocorrências que tenha sido adotado. Na prática, as condições para a verificação objetiva de tal média exigiriam tempos de observação muito mais prolongados que 200 anos;
- Os autores de uma outra parte do texto já são mais rigorosos: "[...] for example, the 0.01 Annual Exceedance Probability threshold (also commonly known as the '100-year flood' with a return period of 100 years, which is better understood as a flood that has a $1 \%$ probability of occurring at any given location in any given year)" (p.201);

- $\quad \mathrm{Na}$ p. 257, os responsáveis por esta parte do texto esclarecem de forma definitiva o conceito em causa mas de modo diferente das anteriores afirmações: "Occasionally, the term "return period" is misinterpreted to mean an event of a particular magnitude, so that an event with a return period of 1 in 20 years having once occurred will occur again only after 20 years have passed. This is incorrect, as at any one time the occurrence of a particular (event) will have a specific probability associated with it. Given this it is entirely possible to have two 1 in 20 year events in successive years or indeed in the same year".

Selecionámos este aspeto porque não obstante o conceito período de retorno ser relevante e muito utilizado na gestão do risco e na comunicação entre especialistas e leigos, o SDRM não está isento de uma falha de coordenação e de rigor que deveria ter sido detetada numa revisão.

\section{Sistematização dos Riscos mais Relevantes}

O Capítulo 3 descreve, de um modo sistemático ou estruturado, um conjunto selecionado de riscos associados a catástrofes relevantes. Para o efeito, o Capítulo desdobra-se nas quatro Secções seguintes:

- Secção I - Riscos Geofísicos (sismos, atividade vulcânica e tsunamis);

- Secção II - Riscos Hidrológicos (cheias, deslizamentos de terras, a ação de ondas e inundações costeiras);

- Secção III - Riscos Meteorológicos, Climatológicos e Biológicos (ciclones, tempestades convectivas e temperaturas extremas, secas, incêndios florestais e rurais e epidemias);

- Secção IV - Riscos Tecnológicos (químicos, nucleares e efeitos secundários tecnológicos provocados pelo impacto de processos naturais - riscos Natech em língua inglesa).

A seleção dos riscos adotada pelo SDRM não pretende ser exaustiva. Com efeito, não será difícil a um leitor encontrar algum tipo de risco que poderia ter sido considerado e não foi. Os riscos geofísicos, hidrológicos e meteorológicos estão bem exemplificados por tipos de eventos que são relevantes no contexto de catástrofes a nível mundial. Contudo, na Secção IV, referente a riscos tecnológicos, parece ser pertinente referir alguns tipos de catástrofes que poderiam ter sido considerados como, por exemplo, 
os acidentes (rotura) em barragens, nomeadamente os provocados por cheias excepcionais, ou os acidentes em sistemas de transporte (e.g. acidentes de aviação).

No fim de cada Secção, os autores respetivos apresentam recomendações úteis que sintetizam o exposto e um conjunto numeroso de referências bibliográficas recentes.

A aplicação aos diferentes tipos de risco da metodologia de avaliação, análise e redução de risco de catástrofes referida no Capítulo 2 não é completa e uniforme. Com efeito, enquanto, na Secção I a modelação dos riscos apresentada inclui as componentes da análise quantitativa completa, como é o caso do risco sísmico, noutras Secções e em outros tipos de risco a descrição baseia-se, fundamentalmente, em metodologias próprias desenvolvidas autonomamente e incide em aspetos considerados mais adequados a cada caso.

\section{"Wildfires"}

Exemplificamos para o caso do risco associado a incêndios florestais e rurais ${ }^{8}$. O SDRM designa este risco climatológico por "wildfire" mostrando as definições diferentes que existem. De acordo com o texto (p.295), o termo "wildfire" é considerado mais geral que o termo incêndio florestal o qual é definido pela UE como sendo um incêndio que se propaga por um terreno com qualquer tipo de coberto e afeta áreas florestais (definidas de acordo com a FAO). Constata-se a dificuldade em adotar a terminologia apresentada e proposta no Capítulo 2 para o Risco. De entre as definições para o Risco exemplificadas está a da ISO 31000: "Efeito da incerteza nos objetivos". Esta definição tão geral e abstrata parece estar deslocada numa aplicação tão específica. Defende-se a gestão integrada do fogo e dos combustíveis para redução do número de ignições o que poderá ser entendido como diminuição da Vulnerabilidade. São referidos como fatores desfavoráveis a seca prolongada e as ondas de calor. Não é, contudo, referido o regime de ventos.

Sem fazer a referência aos conceitos de "multihazards" e "multirisks" apresentados no Capítulo 2, o texto faz referência a consequências danosas resultantes deste tipo de incêndios como são os efeitos nas cheias, na erosão do solo e na saúde pública (poluição).

O SDRM aponta dois fatores que podem justificar um agravamento deste tipo de catástrofe: os efeitos da mudança climática e as consequências da deslocação da população das zonas rurais para zonas urbanas. Apesar de não ser referido no texto mas tentando enquadrar estes fatores na metodologia do Capítulo 2, pode-se considerar que esta deslocação tem dois efeitos opostos: diminuição de potenciais danos e perdas pessoais (e. g. habitações), o que significa menos Exposição, e menor capacidade de gestão do combustível e das florestas e menor capacidade para atuação no controlo das ignições, o que significa maior Vulnerabilidade.

Os efeitos da mudança climática devem propiciar uma probabilidade maior de ignições e de condições para mais ocorrências de incêndios intensos. São referidos alguns exemplos mas não é fornecida uma informação quantificada sobre esta alteração nas condições ambientais. É dada mais ênfase aos aspetos sociais e à carência de investigação neste domínio por parte das ciências sociais. Uma alteração no comportamento humano poderá diminuir a Vulnerabilidade.

No que respeita à componente do conhecimento, um dos pilares do SDRM, é salientada a falta de critérios comuns de avaliação do risco deste tipo de catástrofes e a necessidade de ligar bem a investigação científica com a experiência operacional. Na componente de inovação refere-se o uso da modelação computacional para apoio ao combate (gestão de crise), o desenvolvimento de plataformas abertas para alertas precoces à população exposta proporcionando menor Vulnerabilidade e, eventualmente, menor Exposição em situação de crise (auto-evacuação ou refúgio seguro). Integração das medidas de redução do risco, de prontidão, de resposta e de recuperação pós - $\mathrm{crise}^{9}$ mas sublinhando a necessidade da participação ativa da comunidade e de investimento na prevenção (gestão da floresta). Finalmente a necessidade de cooperação internacional.

Com este exemplo mostra-se que a coordenação metodológica coerente dos diversos temas abordados no Capítulo 3 não foi totalmente conseguida porque abrangem domínios técnicos que têm evoluído de uma forma autónoma e a equipa do SDRM não teria a disponibilidade para uma revisão e harmonização completa ou mais avançada ${ }^{10}$.

\section{Comunicação do Risco de Catástrofe}

O Capítulo 4 apresenta o "estado da arte" em comunicação do risco de catástrofes e foca aspetos relevantes no domínio da psicologia social e dos processos de decisão. Assim, são desenvolvidos quatro tópicos destacados:

- Percepção pública do risco;

- $\quad$ Processo de decisão em ambiente de incerteza;

- Comunicação para a "última milha” (para uma zona em situação de catástrofe ou crise);

- Boas práticas e inovação na Comunicação do Risco.

8 Escolha muito motivada pelo período de incêndios deste tipo em Portugal no Verão de 2017. Um dos co-autores deste sub-capítulo é um distinto especialista português, o prof. Domingos Xavier da Universidade de Coimbra.

9 Em Portugal, após o verão de 2017, estes temas estão a ser objeto de muita reflexão.

10 As pequenas falhas ocorrem: por exemplo, a Figura 3.48 (p.297) diz respeito a secas e não a incêndios. 
Compreender o modo como as pessoas têm a percepção dos riscos é fundamental para o sucesso da comunicação. 0 tipo tradicional de comunicar os riscos às populações era a partir de uma entidade emissora, com ascendência resultante do conhecimento especializado e poder político, para um receptor coletivo, a população, com menos conhecimentos e que deveria subordinar-se às informações transmitidas. O SDRM designa este modelo tradicional como o "modelo de deficit". Desde há uns anos ocorre uma mudança substancial, nomeadamente nos países da Europa. Nesta nova situação manifestase um "direito a conhecer" e um enfoque mais forte na "responsabilização individual do cidadão"11 ou seja uma maior participação dos cidadãos para enfrentar as catástrofes ${ }^{12}$. Como forma de sistematizar as diferentes tendências nos modos de comunicar o risco, o SDRM apresenta quatro tipos diferenciados de comunicação do risco: mensagem do risco; diálogo acerca do risco; mensagem governamental; e mensagem instrumental.

A mensagem do risco transmite a informação num sentido (“one-way”) pretendendo-se que a informação não sofra distorções ou mal-entendidos por quem a receba (ex: mapas de risco).

O diálogo acerca do risco aceita que o emissor e o receptor tenham capacidades para participarem em conjunto no processodedecisãorelativoaumrisco ("two-way"). Associa-se, assim, a capacidade de conhecimento aprofundado

e especializado ao conhecimento local e individual. Uma base de confiança mútua pode e deve ser, então, conseguida.

O tipo de comunicação governamental pretende mudar determinadas atitudes consideradas ou comportamentos da população considerados prejudiciais. É um canal de comunicação de tipo "one-way".

O tipo de comunicação instrumentalista pretende, também, mudar o comportamento das pessoas por forma a minimizar algum risco, mas tem a preocupação em perceber a interação entre a informação e as atitudes do receptor, bem como em compreender os fatores que podem motivar a autorresponsabilização pretendida (ex: folhetos pedagógicos que incentivam a autoproteção).

De acordo com o SDRM, a comunicação que não permita um diálogo fica limitada na capacidade de mobilização para uma auto-preparação e proteção. Refere-se que um conjunto fixo de mensagens emitido para uma população pode não ser compreendido do mesmo modo por todas as pessoas. A interação permite a adaptação e o entendimento. No entanto, a informação num só sentido (“one-way") pode também ter efeitos positivos. 0 aspeto importante não é tanto a informação em si mas o contexto local (subculturas de catástrofe) em que é recebido.

As crenças cognitivas e os sentimentos são fatores importantes na previsão de atitudes e são desencadeados pelo enquadramento que tiver a informação do risco na mensagem enviada.

No caso de uma ameaça iminente, em situação de crise, as autoridades necessitam de canais de comunicação que possam transmitir rapidamente alertas com rigor a um número elevado de pessoas expostas. O SDRM assinala, para esta situação, a utilização dos Alerta de Emergência sem Fios (Wireless Emergency Alerts- WEA).

$\mathrm{Na}$ atualidade, a utilização de telefones móveis (ex: sms) para este efeito é um dos exemplos apresentados. Parece que esta é uma solução promissora que permite o envio de indicações personalizadas tendo em conta a localização exata do receptor. Os efeitos e a eficácia destes meios merecem mais estudos e investigação.

Um outro tipo de canal de comunicação importante é o conjunto de redes sociais (Twitter, Facebook, blogs, etc.) que também permite o envio de indicações orientadas para determinados grupos de cidadãos e possibilita um diálogo.

Finalmente, o papel relevante da comunicação social que pode adaptar-se a qualquer dos quatro tipos de comunicação referidos anteriormente. Trata-se de um meio de informação com grande importância e muito influente nos comportamentos e na percepção dos cidadãos.

O subcapítulo seguinte é dedicado aos processos de decisão sujeitos a incertezas inerentes à ocorrência e à evolução dos acontecimentos. Para superar as incertezas utilizam-se modelos e dados de diferentes origens. Dados heterogéneos que podem também suscitar problemas de consistência e de rigor. A análise e gestão de uma grande quantidade de dados (época de tratamento automático de dados - "big data") justifica propostas de novas estratégias de decisão a par das possibilidades de participação por parte dos cidadãos.

As incertezas afetam de maneira relevante os processos de decisão. As incertezas de tipo aleatório podem ser caraterizadas por probabilidades. Contudo, há que entender as hipóteses de base e as incertezas associadas

11 Em Portugal, os cidadãos colaboram quando tal é necessário, nomeadamente para defesa dos seus bens ou na defesa de vidas humanas. A ideia de colaboração ativa dos cidadãos em situação de crise ou de catástrofe ainda não está bem estruturada e interiorizada. Prevalece ainda a ideia que proteção deve estar quase exclusivamente a cargo dos bombeiros ou da proteção civil.

12 Em Portugal também se verifica esta tendência para o "direito a conhecer", em particular através da atuação da comunicação social que, para além de informarem os factos, não se coíbe de fazer críticas à condução das operações em época de crise, mesmo pondo em causa a confiança na proteção civil (exemplo do que ocorreu com os incêndios no Verão de 2017). Tal como é referido no SDRM para as ações na fase pós-catástrofe (Capítulo 5), poderia ser referida uma conduta de comunicação, em período de crise, subordinada a princípios éticos excepcionais 
aos modelos probabilísticos. Os modelos automáticos ou baseados em análises remotas com utilização de satélites e de inteligência artificial ou em análises de informações baseadas em Twitter têm incertezas diversas.

O SDRM assinala a ligação forte entre incerteza, informação e poder. A posse de informação pode conduzir a manipulações resultantes do poder e das capacidades associadas de manipulação. Há que tentar diminuir ou controlar as incertezas, mas há barreiras éticas que protegem a privacidade das pessoas. 0 texto desdobra-se em diferentes considerações sobre os diversos tipos de incertezas mas não apresenta um conjunto de recomendações práticas ou operacionais.

Em situação de emergência ou de crise, a comunicação do risco terá que ser dirigida para o grupo específico de cidadãos ameaçado e localizado numa área específica de impacto ou de catástrofe. Esta localização é designada, no subcapítulo do SDRM, por "última milha" (designação usada na área do Oceano Índico relacionada com o sistema instalado de alerta contra tsunamis). Toda uma panóplia de novas tecnologias pode ser utilizada (tecnologias de informação e comunicação) incluindo diversos tipos de monitorização e de redes sociais.

Quando a área de intervenção é muito abrangente e atinge mais do que um país, os diferentes sistemas de tecnologias podem constituir uma limitação na eficácia das medidas de gestão do risco de catástrofe. Esta diferença de "desenvolvimento digital" pode prejudicar as populações mais vulneráveis que não tenham acesso às novas tecnologias. As tecnologias mais avançadas (digitais) deverão ter como objetivo a mobilização do maior número possível de cidadãos e a disseminação eficaz de mensagens de alerta e de ação.

Refere-se no SDRM que o Quadro de Ação de Hyogo (20052015) reconhece que o alerta precoce é um instrumento eficaz para reduzir vulnerabilidades e para melhorar a resposta a catástrofes de origem natural (PIPP natural). Este tipo de alerta deve envolver quatro componentes essenciais:

- Conhecimento do risco, para compreensão de todos os aspetos do risco em causa e definição de prioridades;

- Monitorização, para acompanhar a evolução do risco e das vulnerabilidades;

- Capacidade de resposta, para garantir que em cada nível de atuação é possível reduzir o risco logo que os primeiros sinais de catástrofe sejam detetados;

- Comunicação de avisos, através de mensagens que devem poder ser bem entendidas pelos receptores.

O sistema de alerta precoce compreende duas componentes principais: a infraestrutura de comunicação, que deve ser muito fiável, composta por diferentes plataformas de comunicação (redundância) e tendo garantias de funcionamento durante e pós-catástrofe; e as mensagens que devem ser eficazes a influenciarem a percepção do risco de catástrofe e o comportamento de autoproteção da população-alvo. As mensagens devem conseguir transmitir a importância e as caraterísticas da ameaça e indicar a melhor forma de autoproteção. Estas mensagens devem ser transmitidas de modo a que possam ser captadas pelos diferentes grupos da população, com diferentes meios de comunicação.

Para melhorar a eficácia dos sistemas de alerta precoce preconiza-se um novo paradigma "centrado nas pessoas", em vez de ser centrado em especialistas, e que começou a ser impulsionado pela Organização Meteorológica Mundial e é também preconizado pelo quadro de ação de Hyogo. Deste modo, espera-se que as comunidades sejam mais ativas e possam estar mais preparadas para desenvolverem ações de proteção contra as ameaças identificadas. Este tipo de paradigma exige um processo de preparação junto de cada comunidade por forma a desenvolver a receptividade à participação ativa e as capacidades necessárias para uma resposta eficaz em caso de crise, incluindo a execução de exercícios e simulações.

Para serem eficazes, os avisos e alertas em situação de emergência têm de ter uma sólida base científica e técnica, mas devem também estar fortemente direcionadas para as caraterísticas das pessoas expostas ao risco em causa.

As estações de rádio e de televisão são importantes na transmissão de mensagens de emergência e na divulgação de opiniões pessoais. As redes sociais podem garantir um fluxo de informação constante e um canal de debate nos dois sentidos ("two-way"). A qualidade das informações transmitidas nas redes sociais pode, contudo, gerar incertezas e perturbações. O diálogo torna-se descentralizado e sem hierarquia. Refere-se no SDRM que a população mais jovem é a que mais utiliza as redes sociais. Há, assim, que diversificar os meios de comunicação em situação de crise para poder abranger os diferentes grupos etários, com diferentes hábitos e possibilidades de acesso aos meios de transmissão.

Uma atenção especial deve ser dada à possibilidade de uma eventual manipulação da informação através das redes sociais, nomeadamente na divulgação de boatos maliciosos ou tendenciosos.

No quarto subcapítulo são apresentados 12 princípios de boa prática na comunicação em situação de crise e que eram considerados como fundamentais no início do século XXI.

\section{Gestão dos Riscos de Catástrofes}

O Capítulo 5 é dedicado à prevenção e mitigação de riscos em conformidade com as recomendações de Sendai para a redução do risco (2015-2020). O SDRM sublinha a alteração na orientação adotada para uma gestão do 
risco de catástrofe em oposição à gestão de catástrofes. O que significa uma maior ênfase na preparação contra as catástrofes antes dos mesmos ocorrerem. Neste Capítulo são abordadas as componentes de uma gestão do risco: medidas de prevenção e medidas de mitigação; planeamento para preparação e resposta; recuperação pós-catástrofe; e financiamento para as ações de mitigação e transferência dos riscos.

A prevenção é definida no texto de um modo muito abrangente como sendo o conjunto de medidas para evitar riscos existentes ou novos riscos. O SDRM reforça a importância das ações anteriores às catástrofes considerando que as medidas de prevenção e mitigação de riscos são mais eficazes economicamente do que as intervenções pós-catástrofes (valorização dos benefícios económicos associados às perdas potenciais evitadas). No entanto, os benefícios totais são de tipos diversos e superam a dimensão económica. A redução de desigualdades económicas e da pobreza é um dos aspetos, um dos fatores a ter em conta na mitigação das consequências.

Como é bem conhecido, não é possível eliminar todos os riscos, nomeadamente os associados a fenómenos da natureza, e a sua prevenção consiste, preferencialmente, na redução da exposição e das vulnerabilidades associadas. Nalguns casos poderá também ser possível atenuar as intensidades dos impactos por meio de medidas especiais de proteção local (diminuição da severidade do PIPP). Este tópico tem sido objeto de muitos estudos nas últimas dezenas de anos. A UE participa ativamente neste domínio desenvolvendo e promovendo diversas atividades com interesse teórico e prático conforme é referido no texto.

Como é conhecido, as medidas de mitigação podem ser de dois tipos: estruturais e não-estruturais. De entre estas medidas salienta-se o ordenamento da ocupação do solo como sendo um instrumento fundamental para diminuir ou controlar a exposição de pessoas e bens a determinados riscos. A seleção e implementação de medidas adequadas exigem uma concertação adequada das autoridades a diversos níveis e a participação dos cidadãos. Os meios urbanos suscitam a atenção e mobilizam esforços para que sejam mais resistentes ou resilientes aos riscos mais relevantes (em alguns casos, a indústria dos seguros tem promovido ações de informação). A divulgação de cartas de risco e a definição de zonamentos apropriados é um bom exemplo para orientar a ocupação do solo de acordo com uma gestão racional dos riscos (a implementação da Diretiva das inundações de 2007 é um exemplo deste procedimento).

\section{Proteção Civil e emergências}

No subcapítulo 5.2 é referida a génese e a função das organizações de proteção civil no contexto europeu. No séc. XX, na sequência das organizações de defesa civil criadas durante a $2^{\text {a }}$ Grande Guerra e que continuaram durante a guerra fria, os estados europeus criaram estruturas de comando e coordenação do conjunto de forças destinadas à defesa dos cidadãos face às catástrofes : as organizações e agentes da proteção civil, com o apoio das estruturas militares quando necessário.

O SDRM refere os sistemas de cooperação no âmbito da proteção civil existentes no quadro da UE. A estruturação das organizações de proteção civil entre 1960 e 2000 contou com a influência relevante da ciência. A cooperação internacional no âmbito da proteção civil é considerada indispensável face aos novos desafios globais e tipos de catástrofes, nomeadamente os decorrentes das alterações climáticas. A cooperação em rede transnacional tem sido muito desenvolvida e aplicada em diversas crises que colocaram em risco a segurança dos cidadãos. São referidos exemplos concretos desta cooperação a nível da UE salientando-se alguns sistemas de alerta precoce e de apoio humanitário e económico em caso de catástrofes.

Medidas de mitigação e recuperação e o financiamento

De acordo com o SDRM, a preocupação das sociedades relativamente aos riscos públicos tornou-se tão intensa e crucial que a respetiva gestão e mitigação pode ser encarada como um tipo especial de regulação política: uma "regulação baseada no risco". É mesmo referida uma faceta de governança baseada no risco e na emergência no contexto do período de austeridade e de recursos limitados na UE. Na verdade, o governo do território tende a ser suportado ou influenciado fortemente pela necessidade de uma gestão dos riscos eficaz. As catástrofes podem ser ocasiões para justificar decisões políticas excepcionais. Uma chamada de atenção é feita no texto à problemática do respeito pelos valores e princípios morais e éticos em ambiente de emergência. Nas ações de preparação contra catástrofes há que salvaguardar os princípios éticos da democracia e proceder com equidade social.

A par da participação mais profissional das organizações de coordenação, regista-se a tendência de uma maior participação voluntária dos cidadãos nas tarefas de preparação de medidas e de resposta face a catástrofes. A integração eficaz destes grupos informais de voluntários, muitas vezes mobilizados pelas redes sociais, é um desafio para as autoridades de proteção civil.

A fase de recuperação pós-catástrofe é considerada uma fase muito importante e deve ser objeto de um planeamento, por forma a atender aos efeitos dos impactos sofridos pela comunidade. Impactos físicos no património construído, em pessoas e impactos sociais e ambientais. Não basta proceder a uma reconstrução rápida de edifícios. Os danos e perdas podem ser de 
diferentes tipos. 0 ideal será existir uma preparação pré-catástrofe que potencie a recuperação.

Esta fase da recuperação deve ser aproveitada para iniciar a mitigação do risco que originou a catástrofe e, também, a mitigação de outros riscos futuros, já conhecidos ou novos. Nesta atividade, a participação e integração dos cidadãos é, mais uma vez, desejável. A catástrofe deverá ser aproveitada para implementar medidas que diminuam as vulnerabilidades tendo em conta os ensinamentos recolhidos no local ou os avanços científicos mais recentes.

O SDRM refere exemplos europeus de recuperação, nomeadamente portugueses. A recuperação económica é um dos aspetos mais relevantes ao tentar tornar as crises como novas oportunidades de desenvolvimento. O Capítulo 5 dedica muita atenção à recuperação psicossocial e às doenças mentais associadas aos diversos tipos de traumas mentais decorrentes das catástrofes.

O objetivo de tornar as comunidades mais resistentes (ou resilientes) é aparentemente consensual mas as capacidades de atuação adequada na fase de recuperação dependem de muitos fatores e existem frequentemente obstáculos políticos, sociais e financeiros que dificultam ou impedem a concretização dos objetivos racionais considerados indispensáveis.

O financiamento das medidas de gestão do risco é um dos aspetos mais difíceis. Na verdade o custo das medidas de prevenção ou de mitigação podem rapidamente exceder as capacidades orçamentais públicas e privadas de uma região ou de um país.

Acresce que os benefícios ou o valor acrescentado destas operações são de difícil concretização ou confirmação, o que tem implicado uma participação forte do Estado.

O SDRM apresenta no subcapítulo 5.4 um conjunto de possibilidades financeiras alternativas. A compreensão do tema não é, contudo, muito fácil. A descrição de alguns casos concretos parece até ser um pouco exagerada e de difícil extrapolação para outras situações. Referem-se alguns exemplos deste tipo: a descrição de parcerias público-privadas (provavelmente com partilha do risco mais ou menos equilibrada) ou a descrição do Consórcio de Compensação de Seguros instituído em Espanha em 1954. Esta descrição pode suscitar algumas interrogações ao leitor: será que este instrumento muito concreto não está datado? Será que pode ser um modelo a seguir?

Afigura-se que a questão do financiamento merecia um subcapítulo mais estruturado.

No entanto, o conceito de transferência de riscos com base em seguros é bem conhecido e a referência a modalidades de seguros que propiciam ou compensam a atenuação voluntária de vulnerabilidades é muito oportuna.

\section{Desafios na Gestão do Risco de Desastres}

O Capítulo 6, o último capítulo do SDRM, apresenta uma síntese dos desafios futuros que se colocam a todos os agentes de mitigação do risco de catástrofes, aos especialistas científicos, aos decisores políticos e aos profissionais no que concerne os aspetos de Parcerias, Conhecimento e Inovação. Estes desafios constituem um resumo de tópicos desenvolvidos ao longo do texto e podem servir de referência para atividades futuras de investigação no quadro da UE ou das Nações Unidas

\section{Considerações Finais do Autor da Recensão}

O documento em análise, o SDRM, atinge três objetivos importantes: (I) a divulgação institucional associada com atividades da EU no âmbito da gestão dos riscos, (II) a apresentação consistente da estrutura do conceito Risco e do conjunto de componentes a considerar na análise e gestão dos riscos e, finalmente, (III) a apresentação estruturada de diferentes tipos de riscos de catástrofes, numa visão integrada.

Salientam-se alguns dos aspetos específicos mais positivos do SDRM:

- A preocupação com os efeitos da mudança climática nos padrões das catástrofes;

- A importância da aplicação da ciência e da inovação na gestão dos riscos;

- O sublinhar da importância da percepção social do risco e do estudo dos comportamentos humanos na prevenção e gestão de crises;

- A ênfase dada à comunicação do risco na vertente da eficácia nas informações a fornecer aos cidadãos em risco, aplicando novas tecnologias, e na vertente de manutenção da confiança da comunidade nos serviços de proteção;

- A necessidade de cooperação ativa dos cidadãos e da estruturação da autoproteção dos cidadãos em situação de risco e de perigo;

- A mensagem da necessidade de cooperação internacional para enfrentar as catástrofes que tenham uma escala que ultrapassa a capacidade de um Estado. A cooperação internacional poderá, assim, ser um fator relevante na gestão de crises;

- A abordagem do conceito de multirriscos ou de riscos múltiplos e combinados é relevante do ponto de vista teórico e pode ajudar a estruturar a gestão dos riscos;

- A preocupação com os desafios identificados e as oportunidades de desenvolvimento de soluções através da investigação científica.

Salienta-se a apresentação, ao longo dos Capítulos do SDRM, do "estado dos conhecimentos" o qual é 
sustentado num conjunto muito relevante de referências bibliográficas recentes. É de salientar o facto de o SDRM reunir um número vasto de autores especialistas de várias nacionalidades. Este aspeto deve ter provocado dificuldades na coordenação dos diferentes textos que constituem os sucessivos Capítulos. Conforme foi já referido com o exemplo do período de retorno, o rigor científico e a harmonização de conceitos e metodologias nem sempre estão conseguidos.

Eventualmente como outro reflexo da complexidade de coordenação, regista-se a ausência de um glossário com as definições dos termos adotados ou propostos no documento pelos diferentes autores. Este glossário seria muito útil.

Um documento deste tipo não pode conter toda a informação que é relevante e os temas seleccionados devem ter sido objeto de um escrutínio apertado. No entanto, permitimo-nos assinalar alguns tópicos gerais que entendemos serem faltas relevantes:

- $\quad$ O documento não refere, com a ênfase que julgamos ser adequada, as limitações das medidas de prevenção e proteção face às incertezas e aos processos perigosos com intensidade inusitada, nomeadamente em resultado das referidas alterações climáticas e mudanças na ocupação e utilização do território. A consideração das incertezas aleatórias e epistémicas permitiria evidenciar que a gestão dos riscos de catástrofes não pode ser encarada como um domínio científico ou operacional completamente fiável;

- As limitações decorrentes das capacidades financeiras e das pressões políticas e sociais condicionam os processos de decisão e de mitigação dos riscos impondo critérios, explícitos ou implícitos, de tolerabilidade social aos riscos. Uma apresentação estruturada da economia dos riscos das catástrofes e dos critérios éticos de decisão evidenciaria as dificuldades que podem existir em garantir níveis de segurança mais elevados. A cooperação internacional em situações de crise pode constituir uma ajuda cuja eficácia depende do tipo de catástrofe, de uma cooperação institucional muito avançada e integrada e da escala territorial em causa. Os tempos de resposta podem tornar essa ajuda secundária ou no âmbito de uma gestão pós-crise.

O SDRM pode ser considerado um texto suficientemente completo e atualizado de divulgação da gestão do risco de catástrofes, permitindo uma leitura acessível. 0 SDRM pode ser um ponto de partida para o leitor iniciar um estudo aprofundado e de investigação em áreas que the suscitem algum interesse especial.

Pode dizer-se que o SADRM se situa entre um manual prático de apoio à compreensão da estrutura da análise e gestão do risco de acidentes e uma obra de divulgação de tópicos especiais e de exemplos de aplicação. Neste contexto, o SDRM pode ser sujeito à crítica por ser mais teórico do que prático. Ou seja, é um documento de síntese e de orientação para aprofundamentos em diversos domínios mas não apresenta recomendações operacionais ou dados estatísticos robustos e harmonizados relativos aos diversos tipos de riscos.

A ênfase na aplicação dos conhecimentos científicos e da inovação à gestão dos riscos já deveria ser consensual em pleno séc. XXI. No entanto, constitui um dos vetores principais do SDRM e um objetivo fundamental a atingir. Deste modo, convoca-nos para um renovado esforço em defesa do rigor na interpretação dos factos e de conhecimentos sustentados. Compreende-se que a adaptação à mudança climática é um domínio que exige conhecimentos científicos e uma gestão de incertezas e de vulnerabilidades muito apurada. O SDRM aborda a influência da mudança climática nos diferentes tipos de risco mas não apresenta informações novas muito concretas.

Não sendo um documento que divulgue conhecimentos complexos ou muito avançados, o SDRM cumpre uma função importante no contexto internacional e constitui uma boa apresentação das atividades de gestão dos riscos de catástrofes na União Europeia. 